Toye, C. and Jiwa, M. and Holloway, K. and Horner, B. and Andrews, S. and Mclnerney, F. and Robinson, A. 2015. Can a community of practice enhance a palliative approach for people drawing close to death with dementia? International Journal of Palliative Nursing. 21 (11): pp. 548-556.

\title{
Can a community of practice enhance a palliative approach for people drawing close to
} death with dementia?

\begin{abstract}
This action research study was conducted to trial a strategy intended to support a consistent, high quality, palliative approach for people with dementia drawing close to death - the implementation of a community of practice. Professionals from community/residential care and hospitals formed this community of practice, which took on the role of an action research group. The group was supported to identify and address practice problems. Four action plans were implemented; outcomes from two are reported. When actioning the plan 'Providing education and information for the staff', the staff's ratings of sessions/resources were positive but impacts upon knowledge, views, or confidence were small. When actioning 'Supporting families', families providing care in non-hospital settings received information about severe dementia from suitably prepared staff, plus contact details to access support. Family feedback was primarily positive. Reference to additional practice change frameworks and inclusion of specialist palliative care professionals are recommendations for future initiatives; also focusing on targeted, achievable goals over longer timeframes.
\end{abstract}

\section{Keywords}

Dementia, Palliative care, Evidence translation, Action research, Community of practice 


\section{Introduction}

A palliative approach to care is appropriate in life limiting conditions, including progressive dementias (Dempsey et al., 2015). Palliative care principles are enacted to minimize suffering and distress; maximize quality of life; avoid futile, potentially distressing, interventions; and support the family carer (Toye et al., 2012a). However, the dementia experience is unique to each person and often characterized by comorbid illness (Dempsey et al., 2015). Care needs merit an evidence-based, expert, and individualized approach.

Towards the end-of-life, care may be provided across multiple care settings yet seldom involves palliative care services (Dempsey et al., 2015). Care teams may comprise nurses, doctors, allied health practitioners, care managers, and/or support workers, alongside family carers. A palliative approach can be provided by these teams, as is recommended by evidence-based guidelines (Australian Government, 2006; Australian Government, 2011). However, shared understandings, common goals, and impeccable communication are required within and among services to maximize benefits.

This study was conducted to trial a strategy intended to support a consistent, high quality, palliative approach for people with dementia drawing close to death - the implementation of a Community of Practice (CoP). Objectives included to: identify problems with delivering such an approach; develop and implement plans to address these; and evaluate outcomes for the person with dementia, the family carer, and/or the staff. This work was conducted in Perth, the capital of Western Australia (WA), as part of a larger study.

\section{Background}

A CoP has the potential to facilitate shared understandings, common goals, and improved communication; it is formed by practitioners who have a common domain of interest and meets regularly to develop and share "resources, experiences, stories, tools, and ways of addressing recurring problems" (Palmer and Kramlich, 2011, p. 31). Knowledge exchange is a primary aim, 
with benefits augmented by adequate management of power differentials within the group, support for 'active' participation, and inclusion of members who can span the 'different worlds' represented by members (Hart et al., 2013). In this way, a CoP provides a framework for knowledge integration and translation (Palmer and Kramlich, 2011).

\section{Method}

This study employed Action Research (AR) (Waterman et al., 2001, Stringer and Genat, 2004) to facilitate CoP activities. AR engages participants, in this case CoP members, in a cyclical research process (Stringer and Genat, 2004). In recognition of challenges with delivering a consistent, high quality, palliative approach across settings, partnerships were formed among university based researchers and local service providers delivering acute, residential, and communitybased care for people drawing close to the end of life with dementia (Table 1). The CoP (see also Toye et al., 2012a) was drawn from the partnering organizations and members needed to evidence: commitment to high quality care; a desire to improve outcomes for people living with dementia and drawing close to death, a similar desire to improve outcomes for their family carers, and the capacity to drive practice change. In the study, the term 'people drawing close to death' was defined as 'people for whom death within the next 6 months would not be surprising'.

In an AR cycle, problems are identified by stakeholders in conjunction with researchers, reflection is facilitated to identify actions that may help, and these actions are then undertaken, with outcomes evaluated (Bowling, 2009). In this study, the AR group (the CoP) identified areas for change, drove change, and determined successes. CoP meetings in April/May 2010 involved clarification of the project and planning of monthly meetings. Research phases included: Reconnaissance, Identifying key problems, Planning and taking action, and Evaluation and critical reflection (Toye et al., 2012a) (critical reflection will be reported elsewhere). The research team supported CoP members by: 
1. Facilitating a common understanding of a palliative approach.

2. Facilitating collaborative identification of problems with delivering a high quality, consistent, cross-sector, palliative approach via (a) meeting facilitation and (b) a preliminary investigation of current care producing findings for CoP consideration.

3. Providing evidence-based practice recommendations to help address these problems.

4. Assisting in development/accessing of plans, resources, and tools to implement practice change.

5. Undertaking evaluation of outcomes of change, as agreed with CoP members.

Ethical approval was from the Human Research Ethics Committees of Curtin University (HR41/2010) and the WA South Metropolitan Area Health Service (C/10/246). Inclusion criteria, recruitment and data collection plans, plus planned analyses are in the previously published protocol (Toye et al., 2012b).

\section{Reconnaissance}

The reconnaissance, in mid-2010, involved the following research team strategies:

1. Literature and web-based searches, providing practice recommendations and potentially useful resources to support high quality practice in a palliative approach for people drawing close to death with dementia.

2. A survey of the staff in participating settings, using the Palliative Care Providers' Evaluation Tool (Eagar et al., 2004). This tool evaluates the staff's confidence with palliative care delivery; views on death, dying, and palliative care; and perceived educational needs.

3. Inclusion in the survey of additional items to determine participants' views on issues related to a palliative approach for people experiencing dementia (Figure 1).

4. Analysis of survey findings using descriptive statistics. 
5. Provision of summaries describing relevant organisational practices via: (a) Interviews with key informants from the partnering organisations who held positions that ensured their knowledge of client assessment, care planning, and care interventions. (b) Audits of documents identified by key informants as underpinning, facilitating, or communicating relevant practice..

6. Interviews with current and bereaved family carers eliciting experiences of service delivery, data subjected to constant comparative thematic analysis (Thorne, 2000).

7. Provision of reports for the COP's consideration, summarising reconnaissance findings.

\section{Identifying key problems}

CoP meetings first explored members' perceptions of care related problems impacting upon end-of-life care for people living with dementia. Reports of reconnaissance findings were then presented to members, who refined decision making accordingly.

\section{Planning and taking action}

Planning for change, and the development and accessing of resources to support change, occurred at CoP meetings in late 2010. COP members supported implementation of actions across settings from January until April 2011.

\section{Evaluation}

End of study evaluations (April - June 2011) addressed:

1. The staff's post intervention confidence and views; Wilcoxon Signed Rank Tests examining changes since reconnaissance in areas targeted by actions.

2. The staff's scores from administration of the Dementia Knowledge Assessment Tool Version 2 (Toye et al., 2013) and the Palliative Approach Questionnaire (Andrews, 2010) (another knowledge assessment tool), Wilcoxon Signed Rank Tests comparing 'total correct' scores from immediately before and after staff education sessions. 
3. Views of practice change summarized from staff and family feedback survey responses using descriptive statistics.

4. Views of practice change summarized from 'end of study' interviews conducted with family carers, data subjected to thematic analysis.

\section{Results}

\section{Reconnaissance}

'Care settings' represented in the CoP included one Residential Aged Care Facility (RACF, providing 24 hour nursing care) and a co-located medical practice; two hospital wards designated for the care of older patients, one providing medical and one mental health care; inhome respite and counselling 'arms' of a dementia advocacy and support organization (hereafter called the support organization); and one home care service provider (Table 1).

Sixty professional staff/practitioners (nurses, allied health staff, physicians, and care managers) from across the settings completed reconnaissance surveys. Findings revealed differences in confidence and views across settings of at least a third in a number of key items (Table 2). Education needs identified in $15 \%+$ of the responses from the 60 staff members were:

- end-of-life communication skills,

- dealing with terminal delirium and end-of-life ethics, and

- $\quad$ pain assessment and management.

Findings from the individual, semi-structured, reconnaissance interviews with family carers $(n=8)$ are briefly summarized here. Participants ( 2 husbands, 3 wives, and 3 other relatives) were recruited via residential and support providers but interviews addressed care across all settings. Age groups ranged from 40 to 49 years to 80 years and older. During the period of care considered, the people living with dementia spoken about by these carers had all met Functional Assessment Staging Tool (FAST) criteria for moderately severe or severe dementia (Reisberg, 1988). Findings described challenges faced by family carers in supporting and monitoring care, 
advocating for the individual needs of their relatives, and navigating the health system. To meet these challenges, participants explained requirements for information and other support from providers that needed to be sensitively addressed within the context of trusting relationships.

\section{Identifying key problems}

CoP members initially identified three problems based upon their experience, a need to:

- overcome fear in clients,

- enhance the staff's communication, and

- provide more information for clients' families.

The following opportunities for practice enhancement were identified in the reports provided to CoP members based upon comparisons between actual and recommended practice, and with reference to survey and family carer interview findings:

- providing a more holistic and individualized approach to care;

- supporting families throughout the trajectory and into bereavement;

- delivering family support within the context of a team approach; and

- implementing a policy commitment to palliative care tailored for people experiencing dementia that included staff education.

The CoP's decision was to focus on:

- $\quad$ staff/practitioner knowledge;

- staff/practitioner communication, within teams, among teams, and with families;

- support for clients with dementia to minimize distress and recognize the individual; and

- support for the family carer, mentoring through the care system and the dementia trajectory and providing information relevant to the carer role. 


\section{Planning and taking action}

There were four action plans (see Figures 2 and 3). Plans 3 and 4 could not be implemented in hospital settings during the designated study period because of a lack of patients drawing close to death with dementia at this time. There were 56 clients living with severe dementia and receiving residential or home care during the study period plus 67 family carers for whom support could potentially be provided in these contexts or via the support organisation. There were three client transfers and three client deaths.

Plan 1: Providing education and information for the staff. CoP members prepared staff members (all settings) to enact practice change using education and information designed to maximize consistent understanding of a palliative approach for people drawing close to death with dementia. There were three 'core' education modules for the professional staff, adapted from modules developed for another study (see acknowledgement): dementia as a life limiting condition, palliation and dementia, and communication with family members. Numbers of nurses, allied health professionals, and care managers attending the modules ranged from 76 to $90,44 \%$ to $88 \%$ of those eligible in each setting. Invitations were extended to medical practitioners but none attended. A group of the staff was also designated to address particularly sensitive discussions with families $(n=27)$ and attended a fourth module on grief and loss in dementia, delivered by the support organization. There were three education modules for support workers: dementia as a 'terminal illness' and a dementia palliative care approach for clients and families (parts one and two). Participating organizations delivered these modules together; 114 from the 130 eligible staff attended (86\%). The following existing informational resources were made available to clinical staff in the partnering organizations:

- Components from a Palliative Care Resource Kit offered to the CoP by the Palliative Care Network of the Western Australian Department of Health: medication recommendations, 
information on legal issues, and practice guidelines (Western Australian Palliative Care Network, 2010).

- A booklet about a palliative approach in severe dementia (Curtin Health Innovation Research Institute, 2010), developed by the research team in collaboration with the CoP and the WA Palliative Care Network, with dementia specific information related to pain assessment and management, nutrition and hydration, delirium, and agitation.

Plan 2: Improving the staff's communication. Communication skills were addressed during the staff education. Common understandings promoted in the education and resources were also intended to facilitate consistent communication. Resources developed and/or implemented for Plans 3 and 4 were to support the staff's communication with families.

Plan 3: Minimizing distress in the person experiencing dementia. The CoP addressed implementing symptom management via resources included for Plan 1. A person centred approach to care involved developing and implementing:

- A Client Personal Preference Information Form to document clients' preferences and inform care, particularly upon transfer ( 28 commenced, 9 completed, one used upon transfer).

- A Personal Life History Booklet for development by families and/or care workers in residential and community care, based upon a version previously designed by Alzheimer's Australia (South Australia), to help prompt memories and inform care (20 commenced, none completed [but development is lengthy]).

Plan 4: Supporting families. An existing information booklet for family carers of people with severe dementia (Palliative Care Dementia Interface: Enhancing Community Capacity Project, 2007) was provided to 28 families. The CoP's protocol stipulated that the booklet was to be provided in the context of a planned conversation with a suitably prepared staff member (one who had attended 'Grief and Loss in Dementia'), and that there should be options provided to the family for ongoing support. 
An education session for family carers was developed with input from the CoP, based upon the content of the information booklet. Sessions were provided at the RACF, or at support group meetings, to 22 carers. A suitably prepared person needed to present these sessions and, in these instances, a counsellor and a medical practitioner were involved.

An information sheet, listing useful contacts, was developed during the study by the CoP (Family Carer Key Services Contacts List). Thirty families were provided with this form.

\section{Evaluation}

Evaluations for Plan 2 were subsumed into evaluations for the other plans. Evaluations for Plan 3 will be reported elsewhere.

Plan 1. Fifty two staff members completed the 'end of study' staff survey that included the modified Palliative Care Providers' Evaluation Tool (Eagar et al., 2004), 25 responded during both the reconnaissance and evaluation phases: 13 nurses, 5 GPs or allied health staff, and 7 care coordinators or managers. The median number of years of experience in dementia care of this group was 10 (range $0-30)$. The group was predominantly female $(n=22,88 \%)$ and the majority $(n=13,52 \%)$ was aged over 50 years. For this group, there were statistically significant changes in responses, since the reconnaissance, for only two relevant items. There was improved recognition of swallowing difficulties occurring in late stage dementia $(z=-2.76, p=0.006)$ and increased agreement that hospitalization should be avoided in dementia late stage $(z=-2.24$, $p=0.025)$.

Dementia knowledge scores were obtained from 74 participants immediately before and after dementia education: 53 nurses (72\%), 10 allied health staff (14\%), 7 care coordinators/managers (9\%), and 4 students on placement (5\%). Three staff members (4\%) reported attending postgraduate courses on dementia care. Before the education, the median number of items correct, from a possible 21, was 17 (range 9-21), 18 afterwards (range 13-21) ( $z=3.11, p=0.002$ ). 
Knowledge of palliative approach scores were obtained from 72 participants in the palliative care education, three fewer nurses and one additional care coordinator/manager compared with the previous sub-sample. Two of the staff (3\%) reported attending palliative care courses. The median number of items correct from a possible 26 before the education was 21.5 (range 14-26), 23 afterwards (range 17-26) $(z=6.13, p<0.001)$.

Most of the staff attending education evaluated sessions positively (Tables 3 and 4). The third module for professionals introduced the family carer information booklet (Palliative Care Dementia Interface: Enhancing Community Capacity Project, 2007). Nineteen of the 74 staff responding after the session (26\%) were concerned that the booklet might be overwhelming for families, eight (11\%) thought it might cause anxiety, and $12(16 \%)$ felt it might be confronting. However, at least $78 \%(n=58)$ indicated that the booklet would help families, help staff to explain dementia to families and support workers, improve families' understanding of severe dementia, help families make decisions, and be easy for families to understand.

At the end of the study, the two informational resources for the staff (booklet and resource kit) received mainly positive evaluations ( $n=27,52 \%$ of those surveyed). See Table 5 .

Plan 4. Surveys were mailed to the 41 family carers included in the implementation who could be accessed; 12 were returned (29\%) from 6 wives, 4 daughters, and 2 husbands. Five family carers were included in end of study interviews considering the use of the new resources; two wives, two daughters, and one male relative, all recruited via the RACF and support organizations.

All family carers rating the information booklet addressing severe dementia using the questionnaire (9 from 28 recipients, 32\%) indicated that it was helpful and easy to understand. Two respondents reported that sections of the booklet made them feel anxious; one found it overwhelming and one confronting. Six respondents said that the booklet improved their understanding of dementia and eight that it helped them understand decisions they would need 
to make, with seven saying they would find it helpful in the future. Six respondents said that it made them feel more comfortable to approach the staff. Two interviewees reported sharing it with their families to enhance shared understanding. Staff members responding to survey questions about this resource at the end of the study rated it positively $(n=15,56 \%$ of the 27 suitably prepared, Table 5).

Family carer information sessions were described at interview as "walking through" the family carer information booklet, promoting discussion on what was expected or wanted at the end of life. The nine respondents rating the session using the questionnaire ( $41 \%$ of attendees) all indicated that the way the session was conducted and the content were helpful.

The Family Carer Key Services Contacts List was unanimously welcomed by all 12 survey respondents. Interviewees explained that the resource would be more useful earlier in the dementia trajectory.

\section{Discussion}

In this study, a research team supported a CoP aiming to develop and implement a consistent, high quality, palliative approach for people drawing close to death with dementia across local care settings. An AR methodology was used in which the CoP formed the AR group. Four action plans were implemented and two are evaluated in this paper.

A palliative approach is widely recommended as a framework for care delivery to people who are drawing close to death with dementia (Gove et al., 2010, National Institute for Clinical Excellence, 2006, Australian Government, 2006, Australian Government, 2011) and transfers across care settings can be anticipated. Nonetheless, avoiding care fragmentation and inconsistent, sub-optimal, implementation of practice recommendations for this vulnerable group, and for their family carers, remains a challenge. This approach to driving practice change was intended to draw upon the evidence and the expertise of committed professionals to 
identify targeted areas upon which to focus. These professionals then planned and implemented the required actions.

Despite a suite of plans, only small changes were achieved. In particular, improvements in staff knowledge, views, and confidence were small. In addition, the plan to address family carer support could only be implemented in residential and community settings within the study period. The limitations to this work merit consideration for the instigation of future CoP driven change in this area.

Three limitations relate to the CoP itself: needs to support 'active' CoP participation, requirements for management of power differentials within the group, and likely benefits from the inclusion of members spanning 'different worlds' (Hart et al., 2013) (eg, hospitals versus residential care). First, it was not feasible for the hospital-based CoP members to implement planned practice changes during the relatively brief study period. In this way, the active participation of the hospital based CoP members was constrained, despite involvement in decision making and education delivery. Second, physicians' engagement with staff education sessions did not occur. It is critical that attempts to change practice engage with all practitioner groups to address care consistency but, in this study, the medical perspective was underrepresented within the CoP. Third, there was a lack of specialist palliative care expertise in the CoP. Specialist palliative care expertise spanning community, residential, and hospital settings might have drawn together CoP members in a more united approach to target particularly critical issues.

A fourth limitation to this work was the failure of the researchers to engage adequately with elements of the literature that might have further informed practice change. For example, motivation, capacity, and opportunity are regarded as key elements that need to be addressed if behavioural change is to be achieved (Michie et al., 2011). This study addressed the capacity for the staff to change their behaviours by providing them with education and resources. 
However, a failure to address considerations of staff motivation and opportunities in more depth at the planning stage may have contributed to COP decisions to attempt wide-ranging and hence unwieldy change within the study timeframe.

Finally, even changing workforce views and confidence related to palliative care was difficult. A small group of staff participants responded to surveys in both reconnaissance and evaluation phases and significant changes were minimal. Embedding evidence into practice is a complex and challenging area, with interactions between evidence and context influenced by individuals and care teams (Rycroft-Malone et al., 2013). Frequent personnel changes pose a significant challenge to evidence translation.

This study did test resources, although feedback from the staff and families was limited. The family carer booklet was evaluated in a previous study involving 233 family carers (Chang et al., 2010). Findings of the current study were consistent with those from that work in which $97 \%$ of the family carers found the booklet to be helpful and $98 \%$ found it easy to understand. In the previous study, family carers were included from across the dementia trajectory and 100 (43\%) indicated that the booklet should have been provided at diagnosis; $86 \%$ believed that the booklet should be freely available. In the current study, suitably prepared staff provided the booklet in a supportive context. The CoP targeted family carers for whom bereavement was likely imminent. Given this altered context, and that a minority of the family carers found the booklet confronting or overwhelming, distribution plans were well-justified.

Some study limitations issues have since been addressed. The failure to engage physicians in education sessions resulted in delivery of post-study sessions to family doctors. Although there was insufficient capacity for ongoing action research cycles, the government funded Australian Dementia Training Study Centre continued to promote practice enhancement using the CoP model. In this small way, the approach adopted for this study provided a catalyst for change in the local community. 


\section{Conclusions}

This study has begun to explore the extent to which a CoP can enhance a palliative approach for people approaching death with dementia. Practice change was achieved, but limited. The potential for CoP initiatives to work in this area is clear but greater attention to CoP dynamics and the complexities of driving practice change is required to maximize positive outcomes. Carefully targeting focused, and probably incremental, change over a lengthier time period is recommended to address the clearly identified need for a consistent, high quality, palliative approach for people approaching death with dementia. 


\section{References}

Andrews S (2010) Behind the blue door: Developing the Practices of Aged Care Staff Around a Palliative Approach in a Dementia Special Care Unit. PhD thesis. Available from Library Open Repository, University of Tasmania, http://eprints.utas.edu.au/19307/.

Australian Government (2006) Guidelines For a Palliative Approach in Residential Aged Care: Enhanced Version. Department of Health and Ageing, Australian Government, Canberra, Australian Capital Territory, Australia. Available from https://www.nhmrc.gov.au/guidelinespublications/ac15.

Australian Government (2011) Guidelines for a Palliative Approach for Aged Care in the Community Setting: Best Practice Guidelines for the Australian Context. Department of Health and Ageing, Australian Government, Canberra, Australian Capital Territory, Australia. Available from http://www.health.gov.au/internet/main/publishing.nsf/Content/palliativecare-pubsorder-form-htm.

Bowling A (2009) Research Methods in Health ( $3^{\text {rd }}$ ed). Open University Press, McGraw Hill Education, Maidenhead, England and Two Penn, Plaza, New York, USA.

Chang E, Easterbrook S, Hancock K, Johnson A, Davidson P (2010) Evaluation of an information booklet for caregivers of people with dementia: An Australian perspective. Nurs Health Sci 12: 45-51.

Curtin Health Innovation Research Institute (2010) Key Elements of a Palliative Approach for People with Severe and End Stage Dementia: A Booklet Developed for Health Care Professionals. Available from

http://www.caresearch.com.au/caresearch/portals/0/documents/whatispalliativecare/Nation alProgram/PCDementiaCOP/COP-D1-Resource Recommendations.pdf.

Dempsey L, Dowling M, Larkin P, Murphy K (2015) The unmet palliative care needs of those dying with dementia. Int J Palliat Nurs 21: 126-133. 
Eagar K, Senior K, Fildes D et al (2004) The Palliative Care Evaluation Tool Kit: A Compendium of Tools to Aid in the Evaluation of Palliative Care Projects. University of Wollongong, Wollongong, New South Wales, Australia. Available from research-pubs@uow.edu.au. Gove D, Sparr S, Dos Santos Bernardo AMC (2010) Recommendations on end-of-life care for people with dementia. J Nutr Health Aging 14: 136-9.

Hart A, Davies C, Aumann K et al (2013) Mobilising knowledge in community-university partnerships: What does a community of practice approach contribute? Contemporary Social Science 8: 278-291.

Michie S, Van Stralen M, West R (2011) The behaviour change wheel: A new method for characterising and designing behaviour change interventions. Implement Sci 6: 1-12. National Institute for Clinical Excellence (2006). Dementia: Supporting people with dementia and their carers in health and social care. Available from http://www.nice.org.uk/cg42. Palliative Care Dementia Interface: Enhancing Community Capacity Project (2007) Dementia Information for Carers, Families and Friends of People with Severe and End Stage Dementia. 2nd edn. University of Western Sydney. Available from http://www.caresearch.com.au/caresearch/portals/0/documents/whatispalliativecare/Nation alProgram/PCDementiaCOP/COP-D1-Resource Recommendations.pdf.

Palmer D, Kramlich D (2011) An introduction to the Multisystem Model of Knowledge Integration and Translation. Adv Nurs Sci 34: 29-38.

Reisberg B (1988) Functional assessment staging (FAST). Psychopharmacol Bull 24: 653-9. Rycroft-Malone J, Seers K, Chandler J (2013) The role of evidence, context, and facilitation in an implementation trial: Implications for the development of the PARIHS framework. Implement Sci [Online] 8. Available from http://www.implementationscience.com/content/8/1/28. 
Stringer E, Genat W (2004) Action Research in Health. Merrill Prentice Hall, Upper Saddle River, NJ.

Thorne S (2000) Data analysis in qualitative research. Evidence-Based Nursing 3: 68-70.

Toye C, Blackwell S, Maher S et al (2012a). Guidelines for a palliative approach for aged care in the community setting: A suite of resources. Australas Med J 5: 569-574.

Toye C, Lester L, Popescu A, McInerney F, Andrews S, Robinson AL (2014). Dementia

Knowledge Assessment Tool: Development and preliminary testing with aged care staff and family carers. Dementia 13: 248-256

Toye C, Robinson AL, Jiwa M et al (2012b). Developing and testing a strategy to enhance a palliative approach and care continuity for people who have dementia: Study overview and protocol. BMC Palliat Care 11: 1-8.

Waterman H, Tillen D, Dickson R, De Koning K (2001) Action research: A systematic review and guidance for assessment. Health Technol Assess 5: iii-157.

Western Australian Palliative Care Network 2010. Palliative Care Resource Kit. Department of Health of Western Australia. Available from

http://www.caresearch.com.au/caresearch/portals/0/documents/whatispalliativecare/Nation alProgram/PCDementiaCOP/COP-D1-Resource Recommendations.pdf. 
Table 1 Community of Practice membership

\begin{tabular}{|c|c|c|c|}
\hline Partner & Setting for service & Relevant services & CoP members \\
\hline $\begin{array}{l}\text { Home care service } \\
\text { provider (aged } \\
\text { care). }\end{array}$ & $\begin{array}{l}\text { Clients' homes in local } \\
\text { area. }\end{array}$ & $\begin{array}{l}\text { Personal care, nursing, } \\
\text { home help, allied health. }\end{array}$ & $\begin{array}{l}\text { A nurse and a } \\
\text { care manager. }\end{array}$ \\
\hline $\begin{array}{l}\text { Dementia advocacy } \\
\text { and support } \\
\text { organisation (in- } \\
\text { home respite* and } \\
\text { counselling arms). }\end{array}$ & $\begin{array}{l}\text { Clients' homes in local } \\
\text { area plus local } \\
\text { locations where } \\
\text { services accessed. }\end{array}$ & $\begin{array}{l}\text { In-home respite, } \\
\text { counselling, support, } \\
\text { advocacy, helpline, advice } \\
\text { regarding services. }\end{array}$ & $\begin{array}{l}\text { One care } \\
\text { coordinator. }\end{array}$ \\
\hline $\begin{array}{l}\text { Residential age } \\
\text { care provider. }\end{array}$ & $\begin{array}{l}\text { Local residential } \\
\text { facility with medical } \\
\text { practice. }\end{array}$ & $\begin{array}{l}\text { Personal care, nursing, } \\
\text { allied health \& medical } \\
\text { care. }\end{array}$ & $\begin{array}{l}\text { Two nurses and } \\
\text { a physician. }\end{array}$ \\
\hline Hospital. & Mental health ward. & Ward for older people. & Two nurses. \\
\hline Hospital & $\begin{array}{l}\text { Rehabilitation and } \\
\text { aged care ward }\end{array}$ & $\begin{array}{l}\text { In-patient care, older } \\
\text { people. }\end{array}$ & One nurse. \\
\hline
\end{tabular}




\section{Table 2}

Professional staff reconnaissance survey findings: Variations of at least one third in percent agreement

\begin{tabular}{|c|c|c|c|c|c|}
\hline & $\begin{array}{l}\text { Community } \\
n=6\end{array}$ & $\begin{array}{l}\text { Support } \\
n=8\end{array}$ & $\begin{array}{l}\text { RACF } \\
n=11\end{array}$ & $\begin{array}{l}\text { Hospital: Mental } \\
\text { health } n=12\end{array}$ & $\begin{array}{l}\text { Hospital: Aged } \\
\text { care } n=23\end{array}$ \\
\hline \multicolumn{6}{|l|}{ Agreement with: } \\
\hline $\begin{array}{l}\text { Palliative care standard in } \\
\text { terminal illness }\end{array}$ & 100 & 63 & 100 & 100 & 61 \\
\hline $\begin{array}{l}\text { End-of-life discussion only when } \\
\text { no more curative treatment* }\end{array}$ & 0 & 0 & 9 & 33 & 30 \\
\hline $\begin{array}{l}\text { Palliative care appropriate for } \\
\text { people who have dementia }\end{array}$ & 100 & 75 & 64 & 75 & 61 \\
\hline Confident with: & & & & & \\
\hline $\begin{array}{l}\text { Answering questions about } \\
\text { dying }\end{array}$ & 67 & 13 & 82 & 58 & 61 \\
\hline Informing people of support & 100 & 100 & 82 & 50 & 57 \\
\hline Discussing care options & 100 & 100 & 82 & 75 & 39 \\
\hline Reacting to pain** & 50 & $\mathrm{~N} / \mathrm{A}$ & 82 & 83 & 87 \\
\hline
\end{tabular}


Table 3

Professional staff ratings of education and attendance figures.

\begin{tabular}{|c|c|c|c|c|}
\hline $\begin{array}{l}\text { Professional staff } \\
\text { agreeing/strongly }\end{array}$ & $\begin{array}{l}\text { Dementia } \\
\text { (life limiting) }\end{array}$ & $\begin{array}{l}\text { Palliative } \\
\text { approach }\end{array}$ & $\begin{array}{l}\text { Support for } \\
\text { family carer }\end{array}$ & $\begin{array}{l}\text { Grief and loss } \\
25 \text { respondents }\end{array}$ \\
\hline agreeing n (\%) & $\begin{array}{l}81 \text { respondents } \\
86 \text { attendees }\end{array}$ & $\begin{array}{l}\text { 81respondents } \\
90 \text { attendees }\end{array}$ & $\begin{array}{l}74 \text { respondents } \\
76 \text { attendees }\end{array}$ & 27 attendees \\
\hline Will help provide care & $74(91)$ & $77(95)$ & $59(80)$ & $18(72)$ \\
\hline Will help support families & $75(93)$ & $74(91)$ & $60(81)$ & $19(76)$ \\
\hline $\begin{array}{l}\text { Will support staff } \\
\text { education }\end{array}$ & $75(93)$ & $75(93)$ & $60(81)$ & $15(60)$ \\
\hline
\end{tabular}


Table 4

Support worker ratings of education provided by 95 of the 114 attendees

\begin{tabular}{llll}
\hline $\begin{array}{l}\text { Agreeing or } \\
\text { strongly agreeing }\end{array}$ & $\begin{array}{l}\text { Dementia } \\
\text { (life limiting) }\end{array}$ & $\begin{array}{l}\text { Palliative approach } \\
\text { for dementia: }\end{array}$ & $\begin{array}{l}\text { Palliative approach } \\
\text { for dementia: }\end{array}$ \\
& & $\begin{array}{l}\text { Clients and } \\
\text { families (Part 1) }\end{array}$ & (Part 2) \\
\hline Easy to & $93(98)$ & $93(98)$ & $92(97)$ \\
understand & & $84(88)$ & $91(96)$ \\
Interesting & $92(97)$ & & $68(72)$ \\
New information & $46(48)$ & $57(60)$ & \\
Will help provide & $78(82)$ & $75(79)$ & \\
care & & & \\
Will help support & $76(80)$ & & \\
families & & & \\
\hline
\end{tabular}


Table 5

Staff perspectives of resources after implementation: Survey results

Resource $\quad \%$ of participants rating as useful

Individual items in palliative care kit $(\mathrm{n}=27) \quad 48-67$

Staff booklet $(n=27)$

100 (tailoring palliative care in dementia)

96 (communicating with team \& families)

Family booklet $(n=15)$

100 (staff education, consistent understanding, care)

93 (communicating with team \& families) 
- Dementia is a life limiting condition.

- It is impossible to tell if a person in the later stages of dementia is in pain.

- Difficulty swallowing occurs in people with late stage dementia.

- Palliative care is appropriate for people who have dementia.

- People with late stage dementia should not be admitted to hospital.

- Specialist palliative care services can be useful for people who have dementia.

Figure 1. Items added to the staff survey 


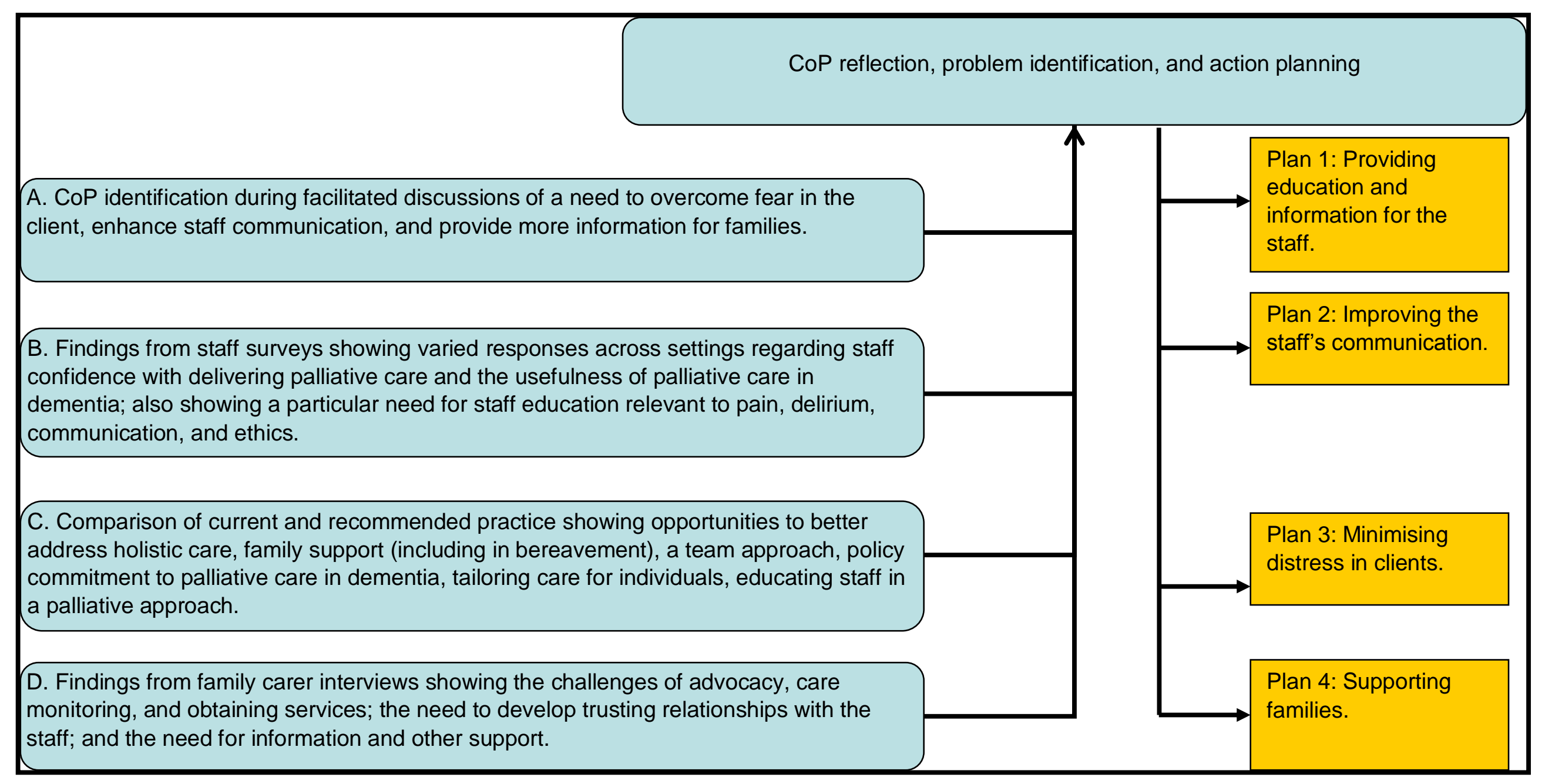

Figure 2. Problem identification and action planning 


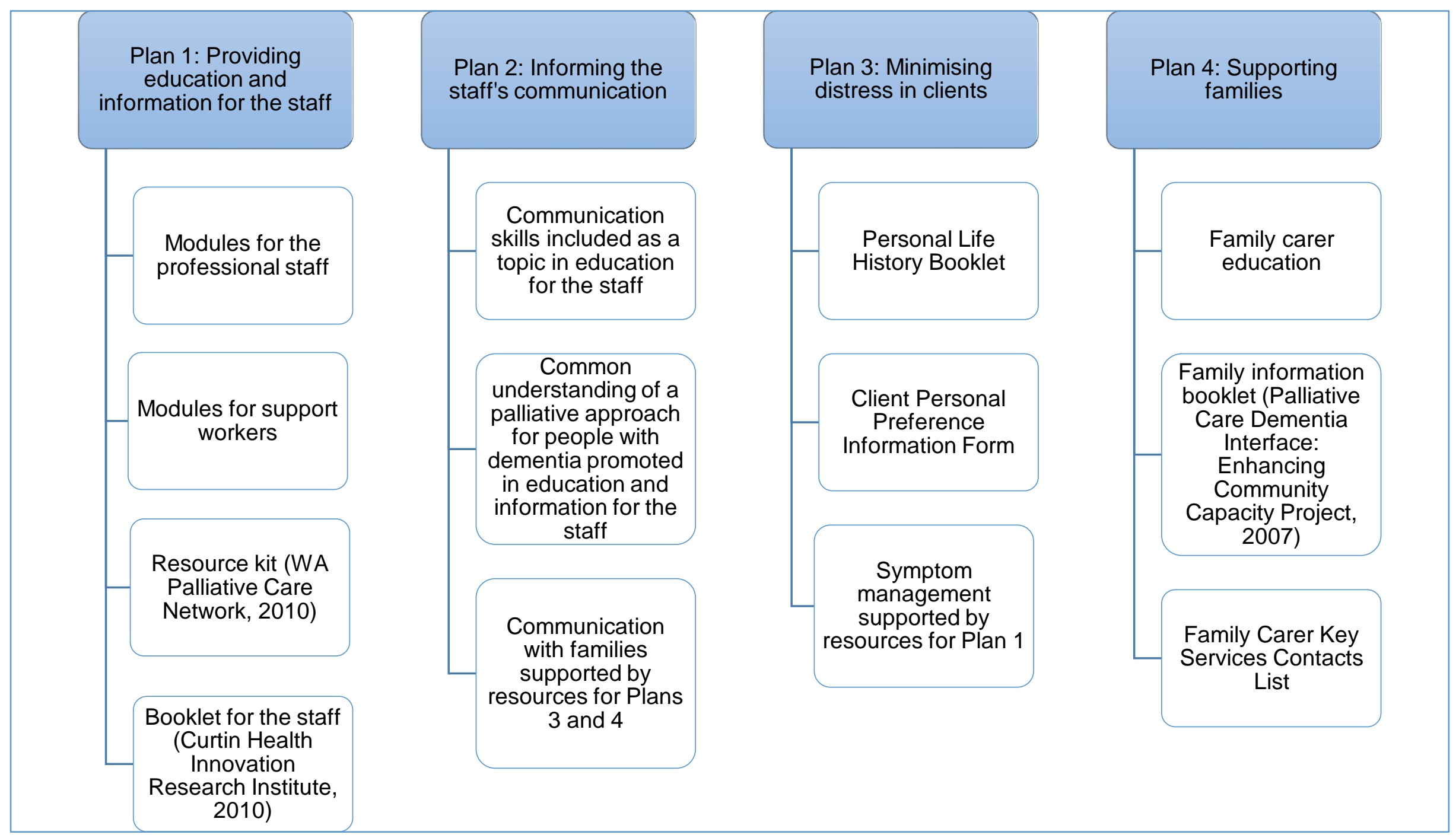

Figure 3. How resources were used to support planned actions 